\title{
Hypothalamic-pituitary-adrenal Axis Dysregulation in Depersonalization Disorder
} \author{
Daphne Simeon, M.D., Orna Guralnik, Psy.D., Margaret Knutelska, M.A., Eric Hollander, M.D.,
} and James Schmeidler, Ph.D.

Background: The purpose of this preliminary study was to investigate HPA axis function in dissociation. Methods: Nine subjects with DSM-IV depersonalization disorder (DPD), without lifetime Posttraumatic Stress Disorder (PTSD) or current major depression, were compared to nine healthy comparison (HC) subjects of comparable age and gender. Results: DPD subjects demonstrated significant hyposuppression to low-dose dexamethasone administration and significantly elevated morning plasma cortisol levels when covaried for depression scores, but no difference in 24-hour urinary cortisol excretion. Dissociation scores powerfully predicted suppression whereas depression scores did not contribute to the prediction. Conclusions: Primary dissociative conditions, such as depersonalization disorder, may be associated with a pattern of HPA axis dysregulation that differs from PTSD and merits further study.

[Neuropsychopharmacology 25:793-795, 2001] (C) 2001 American College of Neuropsychopharmacology. Published by Elsevier Science Inc.
KEY WORDS: Dissociation; Depersonalization; Dexamethasone; Suppression; HPA axis; Cortisol

Given the well-documented traumatic stress history typically associated with dissociation (van Ijzendoorn and Schuengel 1996), hypothalamic-pituitary-adrenal axis functioning in dissociation is of interest. Studies of the neuroendocrinology of dissociative disorders are sparse, yet have suggested possible dysregulation of the HPA axis (Putnam et al. 1991; De Bellis et al. 1994; Lemieux and Coe 1995) which may differ from PTSD (Yehuda 1997). The goal of this pilot study was to investigate HPA axis function in a primary dissociative disorder, depersonalization disorder (Simeon et al. 1997), without complicating comorbidity.

From the Department of Psychiatry, Mount Sinai School of Medicine, New York, NY.

Address correspondence to: Dr. Daphne Simeon, Psychiatry Box 1229, Mount Sinai School of Medicine, One Gustave L. Levy Place, New York NY 10029, Tel.: 212-241-7477, Fax: 212-427-6929, E-mail: daphne.simeon@mssm.edu

Received July 26, 2000; revised April 24, 2001; accepted May 14, 2001.

Online publication: 5/16/01 at www.acnp.org/citations/Npp 051601121

\section{METHODS}

Nine subjects with DSM-IV depersonalization disorder (DPD) without lifetime PTSD or current major depression and nine healthy comparison (HC) subjects without lifetime Axis I or Axis II disorders were independently recruited. After complete description of the study, written informed consent was obtained. Subjects were evaluated by structured interviews for DSM-IV dissociative disorders (Steinberg 1994), other Axis I disorders (First et al. 1995), and Axis II disorders (Pfohl et al. 1995). Subjects completed the Dissociative Experiences Scale (Bernstein and Putnam 1986), which yields a total score "DES," and a depersonalization score "DES-DPS" (Simeon et al. 1998). Depressive symptoms were rated by the 17 -item Hamilton Depression Rating Scale (Hamilton 1960).

Subjects were medically healthy with normal physical examinations and routine laboratory testing, negative urine toxicology and no history of substance abuse. DPD subjects were required to not have taken any psychotropic medications for at least five weeks prior to the study, and were not withdrawn from prior medications for the purpose of participating in the study. In ef- 
fect, five subjects had never received pharmacotherapy, two had remote histories of antidepressant treatment years prior, and two had discontinued medication two months before the study because it had not resulted in depersonalization improvement.

Subjects fasted from 8 P.M. to 8 A.M., ate meals at fixed hours after 8 A.M., and were allowed rest and low-level activity. On Day 1 at 10 P.M. a 24-hour urine collection was commenced. On Day 2 at 8 A.M., blood samples were obtained for measurement of baseline plasma cortisol. At 11 P.M. on Day 2, $0.5 \mathrm{mg}$ oral dexamethasone was administered. At 8 A.M. on Day 3, additional blood samples were obtained for measurement of plasma cortisol. Cortisol concentrations were measured by a double-antibody RIA kit (Diagnostic Products Corporation, Los Angeles), with intra-assay CV 5\% and inter-assay CV 7.5\%.

\section{RESULTS}

The two groups did not differ in age (DPD $30.78 \pm 9.95$, $\mathrm{HC} 31.44 \pm 13.60, \mathrm{t}=0.12, \mathrm{df}=16$, NS) or gender (five males and four females per group). Age of onset of DPD was $15.22 \pm 5.38$ years, with a duration of $11.05 \pm 13.39$ years. On Axis I, one DPD subject had comorbid social phobia, and one had panic and generalized anxiety disorder. On Axis II, one subject had avoidant and one had borderline and narcissistic personality disorder; two were not assessed. The two groups differed significantly in dissociation scores (DES: DPD $25.4 \pm 10.6$, HC $4.2 \pm 2.3, \mathrm{t}=$ $5.88, \mathrm{df}=16, p<.001$; DES-DPS: DPD $56.9 \pm 17.1, \mathrm{HC}$ $1.7 \pm 1.7, \mathrm{t}=9.65, \mathrm{df}=16, p<.001)$. They also differed in depression scores, although these were modest (DPD $8.2 \pm 5.3$, HC $1.4 \pm 1.7, \mathrm{t}=3.67, \mathrm{df}=16, p<.01$ ).

Results are summarized in Table 1 and individually presented in Figure 1. Plasma cortisol levels in the two groups differed significantly following dexamethasone administration, but not at baseline. Similarly, there were no differences in baseline 24-hour urinary cortisol concentrations. When covarying for depression scores, the two groups did significantly differ in baseline plasma cortisol ( $\mathrm{F}=8.81, \mathrm{df}=1,15, p<.01)$ with higher levels in dissociative subjects, but still did not differ in urinary cortisol ( $\mathrm{F}=0.53, \mathrm{df}=1,15, \mathrm{NS}$ ). The DPD group's resistance to dexamethasone remained significant when covarying for depression scores (ANCOVA: $\mathrm{F}=4.23$, $\mathrm{df}=$ $1,15, p<.05)$. For the combined group of subjects, stepwise multiple regression analyses revealed that dissociation/depersonalization scores significantly predicted suppression, while depression scores did not contribute to the prediction (DES: $\mathrm{R}=0.64, \mathrm{~F}=11.30, \mathrm{df}=1, p<$ .01 ; DES-DPS: $\mathrm{R}=0.55, \mathrm{~F}=7.10, \mathrm{df}=1, p<.02$ ).

\section{DISCUSSION}

This is, to our knowledge, the first pilot study investigating HPA axis function in a primary dissociative disorder without complicating comorbid PTSD or depression. There are very few studies examining HPA function in populations with probable or definite dissociation. Lemieux and Coe (1995) found significantly elevated 24-hour urinary cortisol in adult women survivors of childhood sexual abuse with PTSD, but dissociation was not measured. A study by Stein et al. (1997) examined adult women with severe childhood sexual abuse and found significant hypersuppression to low-dose dexamethasone compared to nonvictimized controls. Of the 19 abused subjects 13 had PTSD and 15 dissociative disorders, not allowing dissection of the two conditions. Elevated morning plasma cortisol was reported in sexually abused compared to control girls (Putnam et al. 1991), and 24-hour urinary cortisol tended to be elevated in the same group (De Bellis et al. 1994).

Thus, dissociation may involve a pattern of HPA axis dysregulation which differs from PTSD. The current study suggests that dissociation may be associated with normal or elevated baseline cortisol and diminished negative feedback, while PTSD is associated with reduced baseline cortisol and enhanced negative feedback (Yehuda 1997). Despite the small samples, the power of the test comparing suppression in depersonalized and control subjects was .80 since the effect size, 1.41 , was very large (Cohen 1988). HPA axis dysregulation in dissociation merits further study in larger samples with various dissociative disorder diagnoses.

Table 1. Baseline and Post-Dexamethasone Cortisol Levels in Nine Subjects with Depersonalization Disorder and Nine Healthy Comparison Subjects

\begin{tabular}{|c|c|c|c|c|c|c|c|}
\hline & \multicolumn{2}{|c|}{ DPD } & \multicolumn{2}{|c|}{$\mathrm{HC}$} & \multirow[b]{2}{*}{$\mathbf{t}$} & \multirow[b]{2}{*}{ df } & \multirow[b]{2}{*}{$p$} \\
\hline & Mean & SD & Mean & SD & & & \\
\hline 24-hour urine cortisol ( $\mu \mathrm{g} /$ day) & 94.56 & 37.59 & 79.56 & 27.06 & 0.97 & 16 & .35 \\
\hline Baseline plasma Cortisol ( $\mu \mathrm{g} / \mathrm{dL})$ & 18.48 & 8.46 & 14.57 & 3.66 & 1.27 & 16 & .22 \\
\hline Post-dexamethasone plasma cortisol ( $\mu \mathrm{g} / \mathrm{dL})$ & 7.29 & 6.46 & 1.11 & 1.04 & 2.83 & 16 & $<.05$ \\
\hline Suppression $(\%)$ & 56.47 & 34.88 & 91.88 & 6.71 & 2.99 & 16 & $<.01$ \\
\hline
\end{tabular}



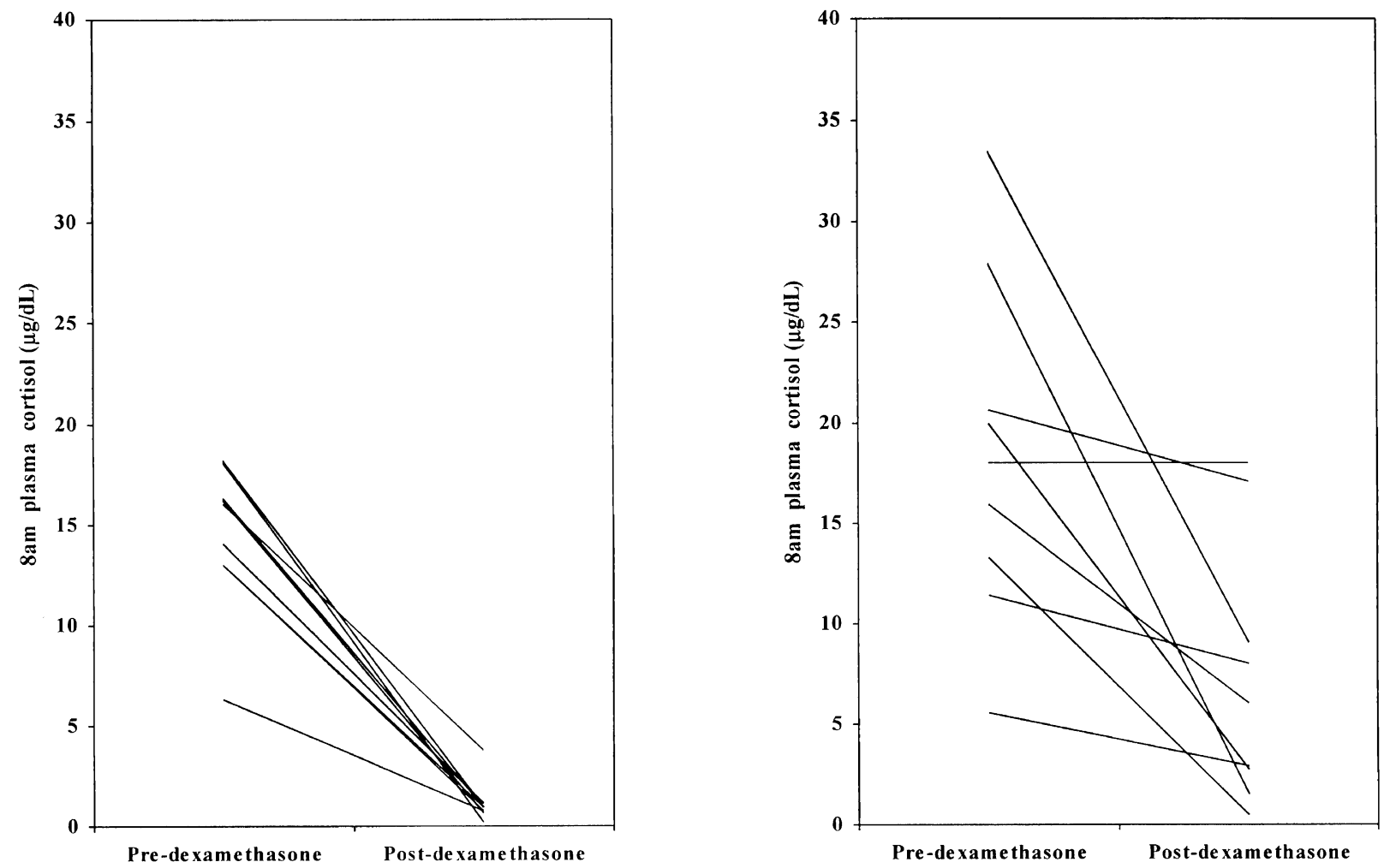

Figure 1. Individual cortisol blood levels before and after the administration of $0.5 \mathrm{mg}$ dexamethasone in nine subjects with depersonalization disorder (right) and nine healthy comparison subjects (left).

\section{ACKNOWLEDGMENTS}

Partly supported by NIMH grant MH-055582 to Dr. Simeon and NIH grant 5 MO1 RR00071 to the Mount Sinai General Clinical Research Center. Presented in part at the Annual Meeting of the American Psychiatric Association New Research, Chicago, May 2000.

\section{REFERENCES}

Bernstein EM, Putnam FW (1986): Development, reliability, and validity of a dissociation scale. J Nerv Ment Dis 174:727-735

Cohen J (1988): Statistical Power Analysis for the Behavioral Sciences, $2^{\text {nd }}$ edition. Hillside, NJ, Lawrence Erlbaum Associates

De Bellis MD, Chrousos GP, Dorn LD, Burke L, Helmers K, Kling MA, Trickett PK, Putnam FW (1994): Hypothalamic-pituitary-adrenal axis dysregulation in sexually abused girls. J Clin Endocrinol Metab 78:249-255

First MB, Spitzer RL, Gibbon M, Williams JBW (1995): Structured Clinical Interview for DSM-IV Axis I Disorders, Patient Version 2. New York, New York State Psychiatric Institute, Biometrics Research

Hamilton M (1960): A rating scale for depression. J Neurol Neurosurg Psychiatry 23:56-61

Lemieux AM, Coe CL (1995): Abuse-related posttraumatic stress disorder: evidence for chronic neuroendocrine activation in women. Psychosom Med 57:105-115

Pfohl B, Blum N, Zimmerman M (1995): Structured Interview for DSM-IV Personality Disorders SIDP-IV. Iowa City, Iowa, Department of Psychiatry, University of Iowa

Putnam FW, Trickett P, Helmers K, Dorn L, Everett B (1991): Cortisol abnormalities in sexually abused girls. Poster presented at the Annual Meeting of the American Psychiatric Association: Washington, D.C.

Simeon D, Gross BA, Guralnik O, Stein DJ, Schmeidler J, Hollander E (1997): Feeling unreal: 30 cases of DSM-III-R depersonalization disorder. Am J Psychiatry 154:1107-1113

Simeon D, Guralnik O, Gross S, Stein DJ, Schmeidler J, Hollander E (1998): The detection and measurement of depersonalization disorder. J Nerv Ment Dis 186:536-542

Stein MB, Yehuda R, Koverola C, Hanna C (1997): Enhanced dexamethasone suppression of plasma cortisol in adult women traumatized by childhood sexual abuse. Biol Psychiatry 42:680-686

Steinberg M (1994): Structured Clinical Interview for DSMIV Dissociative Disorders (SCID-D), revised. Washington, DC, American Psychiatric Press

van Ijzendoorn MH, Schuengel C (1996): The measurement of dissociation in normal and clinical populations: meta-analytic validation of the Dissociative Experiences Scale (DES). Clin Psychol Rev 16:365-382

Yehuda R (1997): Sensitization of the hypothalamic-pituitary-adrenal axis in posttraumatic stress disorder. Annals NY Acad Sci 821:57-75 